\title{
Indicações Geográficas e Desenvolvimento Territorial: Um Diálogo entre a Realidade Europeia e Brasileira*
}

\author{
Flávio Sacco dos Anjos ${ }^{1}$ \\ Encarnación Aguilar Criado ${ }^{2}$ \\ Nádia Velleda Caldas ${ }^{3}$ \\ ${ }^{1}$ Professor do Programa de Pós-Graduação em Ciências Sociais da Universidade Federal de \\ Pelotas. E-mail: flaviosa@ufpel.edu.br \\ ${ }^{2}$ Professora Titular do Departamento de Antropologia Social da Universidade de Sevilha, \\ Espanha. E-mail: eaguilar@us.es \\ ${ }^{3}$ Doutoranda, Programa de Pós-Graduação em Sistemas de Produção Agrícola Familiar, da \\ Universidade Federal de Pelotas. E-mail: velleda.nadia@gmail.com
}

\section{INTRODUÇÃO}

os últimos dez anos o tema das indicações geográficas de produ-
tos agroalimentares converteu-se em assunto de renovado interesse no âmbito dos países latinoamericanos, tanto do ponto de vista estritamente acadêmico quanto na perspectiva da atuação das agências nacionais e, sobretudo, internacionais de fomento e desenvolvimento rural ${ }^{1}$.

Este período coincide com a aparição de diversos estudos e eventos cujo foco é analisar a importância das figuras de proteção dos chamados "produtos com identidade cultural" (vinhos, queijos etc.) para fomentar o desenvolvimento de zonas rurais marcadas pelo isolamento e crise de perspectivas em relação ao futuro. Nesse sentido, coincidimos com Saraceno (2007:167) quando afirma que o entusiasmo despertado

\footnotetext{
* Este trabalho se insere no marco de um Projeto hispano-brasileiro de Cooperação e Intercâmbio existente sob a égide do Acordo CAPES-DGU intitulado "A indicação geográfica como estratégia de desenvolvimento territorial: A experiência espanhola e brasileira". O material reunido em visitas técnicas aos Conselhos Reguladores das indicações geográficas (azeite de oliva, jamón e queijos) na Espanha e no Brasil (Vale dos Vinhedos) e entrevistas (34) realizadas com produtores, empresários e agentes de desenvolvimento (Grupos de Desenvolvimento Local, técnicos da extensão rural) e organizações não governamentais serviu de base para a elaboração do presente trabalho.
}

DADOS - Revista de Ciências Sociais, Rio de Janeiro, vol. 56, no1, 2013, pp. 207 a 236. 
sobre esse assunto nos países latino-americanos é consequência do "êxito inesperado das políticas de desenvolvimento rural" levadas a cabo nos países da União Europeia (UE), onde se destacam os objetivos de coesão territorial e de fortalecimento das identidades culturais. Os impactos que engendram essas novas dinâmicas e esquemas de desenvolvimento são notáveis, tornando-se fonte de inspiração para renovar a atuação estatal em muitos países, incluindo o Brasil.

Não obstante, há uma grande distância que separa o contexto latino-americano do europeu no que afeta ao panorama das indicações geográficas ${ }^{2}$, em toda sua diversidade. Assim, enquanto no primeiro caso apenas foram dados os primeiros passos para o estabelecimento de legislação específica sobre a matéria, coincidindo com o surgimento das primeiras experiências de proteção de produtos agroalimentares, no velho continente há um amplo marco regulador e normativas específicas, tanto no âmbito europeu quanto no plano dos Estados-membros, havendo inclusive outras figuras de proteção ao nível das regiões e autonomias, como é precisamente o caso da Espanha.

Apesar do grande otimismo verificado em ambas latitudes por parte das agências de desenvolvimento implicadas nessas iniciativas, não se pode negar que o tema suscita algumas importantes contradições. Se, por um lado, é capaz de impulsionar processos de coesão social ao nível dos territórios, potencializando ativos intangíveis (Letablier e Delfosse, 1995), também é verdade que pode gerar mecanismos de exclusão para outras coletividades. Esse é o caso de iniciativas que refletem uma flagrante ausência de habilidade social (social skill) requerida para consolidar processos de cooperação e coalizões políticas (Fligstein, 2001:3) mais amplas e duradouras.

Deste modo, não há como desconsiderar outro aspecto que alimenta a polêmica em torno das supostas virtuosidades das indicações geográficas nos países da UE, qual seja, os efeitos deletérios resultantes da proliferação de marcas e figuras de proteção (Barco et alii, 2007; Sanz, 2007). Referimo-nos, entre outras coisas, às dificuldades dos consumidores em reconhecer, de forma clara e inequívoca, as singularidades e os atributos de que, presumivelmente, tais artigos são portadores.

No caso europeu, sob o título de "produtos de qualidade diferenciada" acham-se incluídos não somente os artigos que carregam uma marca diferencial, a exemplo das denominações de origem e das especialida- 
des regionais garantidas, como também os produtos oriundos da produção ecológica e da produção agrícola integrada.

Não obstante, o que parece claro é que não somente são distintas as circunstâncias e os contextos que fazem emergir tais iniciativas em ambos continentes (latino-americano e europeu), mas fundamentalmente a dinâmica que acompanha tais processos e os respectivos resultados que se podem lograr desde a perspectiva de fomentar o desenvolvimento dos territórios. O presente artigo objetiva incidir nesse debate.

Neste trabalho sustentamos a tese de que as indicações geográficas podem converter-se em um importante instrumento para o desenvolvimento de muitas zonas rurais do Brasil, sempre e quando exista uma base conceitual mais ampla, a qual estabeleça a identidade cultural dos territórios no centro das estratégias de intervenção dos entes públicos ou privados interessados nesses processos.

Parte-se aqui da premissa de que não se trata apenas de fortalecer os vínculos verticais da cadeia de valor de um produto típico de um determinado território, mas sobretudo de ampliar os vínculos horizontais que conectam os distintos atores que compartilham traços de uma mesma identidade cultural, como é precisamente o caso dos italianos e de outros grupos étnicos do Sul do Brasil.

Por identidade cultural se entende uma ideia de pertencimento a um determinado grupo social, o que pressupõe compartilhamento de traços culturais, costumes, valores e crenças. Todavia, encontramo-nos frente a um objeto em permanente processo de mutação, que continuamente se recria ao sabor das influências que emergem do mundo exterior, o qual espelha seu caráter imaterial e anônimo pelo simples fato de ser produto de uma coletividade (González, 2006:43).

A saga dos italianos no Brasil meridional é amplamente conhecida na história recente desse país, cujo resgate escapa aos objetivos deste artigo. Nossa ênfase recai na abordagem sobre a trajetória de certos processos levados a termo numa região precisa da geografia gaúcha, em meio à criação da primeira indicação geográfica do Brasil, cuja influência tem sido decisiva para incitar o surgimento de outras iniciativas do gênero no território nacional. Todavia, diferentemente do Brasil, esse assunto goza de uma ampla base de referência nos países da Europa, particularmente dentro do marco das políticas de desenvolvimento rural levadas a cabo no curso das grandes reformas da Política Agrária 
Comum (PAC) e das sucessivas edições do Programa Leader, daí a importância de estabelecer uma a proximação entre ambas as realidades.

Nesse sentido, além dessa breve introdução o presente artigo contempla outras quatro seções. A primeira delas analisa a evolução recente das políticas de desenvolvimento territorial na UE. Essa abordagem torna-se crucial para compreender o contexto atual em que emerge o tema das indicações geográficas, cuja abordagem realizamos, na segunda seção, com ênfase no caso espanhol. A terceira seção examina a questão das indicações geográficas no contexto brasileiro, com especial atenção para o caso do Vale dos Vinhedos, o qual se considera como prototípico para avaliar o estado da questão em nosso país. O exame dessa iniciativa supõe refletir acerca dos limites e possibilidades que nos brindam as indicações geográficas frente ao compromisso de impulsionar o desenvolvimento dos territórios. A quinta e última seção reúne as considerações finais do artigo.

\section{A EVOLUÇÃO RECENTE DAS POLÍTICAS DE DESENVOLVIMENTO TERRITORIAL NA UNIÃO EUROPEIA}

As atuais políticas de desenvolvimento rural implementadas nos países da UE surgiram sobretudo durante os anos 1980, coincidindo com o auge da crise produzida pelos excedentes alimentares. Nesse sentido, as sucessivas reformas da PAC devem ser vistas como um claro reflexo do esforço por reduzir o impacto negativo produzido pelos instrumentos de acompanhamento às políticas de mercado e de sustentação dos preços dos produtos agrícolas.

Durante esse período, desenvolvimento agrícola e desenvolvimento rural eram tomados como se fossem conceitos equivalentes e intercambiáveis entre si. Ou seja, admitia-se à época que o incremento na produtividade dos fatores de produção conduziria, inevitavelmente, à melhoria das rendas agrárias e, consequentemente, ao bem-estar do conjunto dos agricultores e das pessoas residentes nos espaços rurais. O resultado mais evidente consistiu no aumento das desigualdades socioeconômicas entre os países e, inclusive, dentro dos próprios países.

É somente a partir da segunda metade dos anos 1990 que se começa a avançar na consolidação de uma política europeia de desenvolvimento rural autônoma e diferenciada da PAC, por meio da criação dos Programas Leader e Proder ${ }^{3}$. Assim, se a etapa anterior esteve associada ao paradigma da modernização agrária e da centralidade da agricultu- 
ra enquanto objeto do financiamento comunitário, a etapa atual é marcada pelo paradigma da multifuncionalidade, no qual se passa a considerar que o espaço rural deve incorporar outros papéis (ócio, turismo, proteção à biodiversidade etc.) para além da produção agrária stricto sensu $u^{4}$.

Trata-se de uma mudança de orientação importante, através da qual emerge uma nova concepção centrada no território e que, portanto, não mais se destina a apoiar a um setor específico - a agricultura e os agricultores - senão ao conjunto dos atores sociais que interagem nos espaços rurais. Sob o peso dessa perspectiva considera-se que a agricultura já não representa o eixo central ou exclusivo sobre o qual transita a dinâmica dos territórios e que, portanto, cabe impulsionar todas as atividades que contribuam para diversificar e fortalecer o tecido social e produtivo dos espaços rurais.

As políticas com enfoque territorial somente foram concretizadas após a reforma dos fundos estruturais, cujo objetivo fundamental era o de reduzir disparidades entre as zonas europeias mais e menos desenvolvidas. Sua implementação requer a instauração dos chamados partenariados ${ }^{5}$, cuja missão consiste em articular as distintas dimensões institucionais (a União Europeia, o Estado nacional e a região) sob o princípio do cofinanciamento e da subsidiariedade na sustentação material dos projetos.

Decorridos dez anos da Iniciativa Comunitária Leader, surge o Novo Regulamento de Desenvolvimento Rural, com o qual se buscam integrar as concepções agrária e territorial em torno ao segundo pilar da PAC. O objetivo é "evitar a dissociação observada durante os últimos anos entre, de um lado, a agricultura e, de outro, o desenvolvimento rural, procurando recuperar a dimensão territorial da atividade agrária e incorporando a dimensão agrária nas estratégias territoriais de desenvolvimento" (Moyano, 2005:8).

A partir do novo regramento surgem dois novos fundos. O FEGA (Fundo Europeu de Garantia, anterior FEOGA), destinado ao financiamento do primeiro pilar da PAC (a política de mercados), e um outro fundo específico: o FEADER (Fundo Europeu para a Agricultura e Desenvolvimento Rural), orientado à construção do segundo pilar da PAC. Nesse caso, todo o esforço está centrado na geração de emprego (agrícola e não agrícola), na sustentabilidade ambiental, qualidade de vida, fixação da população e no fomento à diversificação dos espaços rurais. 
O fato de contar, pela primeira vez, com uma política de desenvolvimento territorial não se reflete numa destinação de recursos correspondente à grandeza dos objetivos propostos. Por certo, trata-se de uma mudança com a qual apenas foram dados os primeiros passos, tendo em mente que o peso do primeiro pilar da PAC foi sempre dominante. Parece óbvio que a conciliação de interesses não é uma tarefa simples de resolver em meio a um contexto marcado por posições já consolidadas, pela pressão exercida pelas corporações socioprofissionais e por uma disputa em torno de recursos cada vez mais escassos, mormente depois da ampliação no número de países da UE ${ }^{6}$.

A ideia da diversificação supõe o incentivo às atividades não agrícolas e à pluriatividade dos estabelecimentos, ao turismo rural e à criação de pequenas empresas. A geração de empregos, o incentivo à inovação e o resgate de saberes figuram como elementos de destaque no balanço sobre os êxitos das iniciativas Leader. E é justamente nesse contexto que ganha relevo a estratégia de fortalecimento aos produtos com identidade cultural, como é precisamente o caso das indicações geográficas em toda sua riqueza e diversidade. Esse aspecto merece ser ampliado para os efeitos que persegue este artigo.

Vale lembrar que, desde 2007, como resultado do êxito da iniciativa Leader, seu enfoque se integrou à política de desenvolvimento rural da UE, seja em âmbito nacional, seja em âmbito regional. Nesse sentido, é mister frisar que o método Leader descansa sobre sete grandes eixos, a saber:

1) Enfoque territorial. O processo de intervenção leva em conta os recursos e as necessidades de cada território com o objetivo de responder às demandas prementes no marco da política de desenvolvimento;

2) Enfoque ascendente. Em todas as fases do processo as soluções e decisões devem ser assumidas de baixo para cima (bottom up) e não de cima para baixo (top down), como convencionalmente ocorreu, implicando o fomento explícito à participação do conjunto de atores sociais do território;

3) Enfoque associativo e o Grupo de Ação Local (GAL). Constitui-se em organização associativa integrada por agentes públicos e privados que concebem uma estratégia conjunta e um plano de ação para desenvolver uma determinada zona ou território; 
4) Inovação. As ações propostas devem ser inovadoras, podendo ser iniciativas destinadas a fomentar o uso de recursos locais, utilizando novos meios, os quais ofereçam respostas novas aos problemas das zonas rurais ou criem um novo produto, processo ou novas formas de organização no acesso aos mercados.

5) Enfoque integrado. Tem a ver com a necessidade de que as ações e projetos contidos no plano de ação local estejam relacionados como um todo coerente, podendo ser ações relacionadas a um único setor econômico como também aos mais diversos agentes e setores econômicos do ponto de vista social, cultural e ambiental da zona em questão.

6) Criação de redes de cooperação entre zonas. Nesse caso, trata-se de animar o intercâmbio e circulação de informação sobre políticas de desenvolvimento rural, bem como a difusão e transferência de boas práticas e de estratégias inovadoras. A rede Leader implica evitar o isolamento dos GAL, fomentando o diálogo à escala europeia e nacional.

7) Gestão e financiamento local. Consiste em delegar ao GAL a tomada de decisões no que afeta ao financiamento e gestão, levando em conta a necessidade de comprometimento por parte de cada Estado-membro, da região e de todos os atores do território implicados nesses processos.

Dois aspectos merecem ser sublinhados nessa aproximação que fazemos ao Programa Leader. Em primeiro lugar, é mister reafirmar a influência exercida pelo método Leader sobre outras latitudes do planeta. O estudo realizado no México por De los Ríos et alii (2011) representa um exemplo gráfico da multiplicidade de trabalhos ${ }^{7}$ que ilustram tentativas de aplicação deste enfoque nos países latino-americanos.

O segundo aspecto tem a ver com a ênfase na inovação através do uso de recursos locais. Todavia, criar um produto rural não quer dizer, necessariamente, inventar algo novo. A inovação supõe, em muitos casos, resgatar saberes, práticas e/ou processos esquecidos, ao longo do tempo, por uma sociedade onde a padronização e uniformidade se impuseram de forma determinante, sobretudo na esfera agroalimentar. Trata-se, em última instância, de combinar, harmonicamente, tradição e inovação.

Por que são importantes as indicações geográficas para a UE? Tal indagação corresponde à epígrafe de Documento constante do marco euro- 
peu de desenvolvimento rural (UE/MEMO 03/160, 2012) cujo foco da resposta se orienta, entre outros aspectos, para o papel que as IG assumem na conservação do patrimônio cultural, dos métodos tradicionais e dos recursos naturais dos estados-membros, bem como por que elas representam um "signo de valor" que visa satisfazer o gosto de consumidores interessados num produto distinto ao convencional, que é típico e de alta qualidade.

Não é por acaso que boa parte da atuação dos GAL, em diversos países da UE, tem sido no sentido de verdadeiramente garimpar informações que levassem à criação de indicações geográficas. De um ponto de vista geral, pode-se afirmar que este tipo de dispositivo de diferenciação representa a busca de alternativas para aquelas zonas submetidas ao impacto dos processos de reestruturação da agricultura. Nesse caso, a agregação de valor aos produtos é vista como uma via capaz de resgatar os vínculos com o território e fortalecer a identidade sociocultural dos grupos envolvidos.

Não é por outro motivo que a promoção de tais produtos é assumida como uma estratégia viável para reduzir excedentes, dinamizar socioeconomicamente as regiões menos competitivas e marginais e dotar as pequenas explorações e empresas de uma ferramenta com a qual possam diferenciar-se e competir nos mercados globais (Lozano, 2009:24). Essa dinâmica é fortalecida pela emergência de um novo perfil de consumidor interessado em produtos cujo ato de consumo não produza apenas uma apropriação tangível do mesmo, mas que fundamentalmente promova distintos tipos de sensações: sensoriais, emocionais, comunicativas (Aguilar et alii, 2003:170).

São estes os aspectos que emolduram o cenário mais amplo em que se inscreve o tema das indicações geográficas no contexto das políticas de desenvolvimento rural da União Europeia, cuja abordagem, ainda que esquemática, torna-se crucial para compreender os elementos que a seguir analisaremos.

\section{AS INDICAÇÕES GEOGRÁFICAS NA EUROPA E ESPANHA}

Em resumidas contas, pode-se dizer que o último decênio esteve marcado pela crise do padrão da quantidade (Hervieu, 1996) e sua paulatina substituição por um novo modelo no qual a qualidade dos produtos e processos converte-se na tônica dominante. De outro modo, pode-se dizer que o aludido período esteve associado à substituição de uma 
economia de volume por uma economia de valor, mediante a geração de produtos intensivos em conhecimentos (Aguilar et alii, 2003:177).

Por outro lado, os fatos mostram que nos encontramos diante de um novo discurso sobre a ruralidade, o qual se encaixa perfeitamente nas teses que advogam em favor das virtudes dos produtos, processos e serviços com identidade cultural. Tais premissas constam no "Livro Verde sobre a qualidade dos produtos agrícolas, normas de comercialização, requisitos de produção e regimes de qualidade" da Comissão das Comunidades Europeias, o qual refere que os agricultores, em lugar de perceberem as crescentes exigências como uma carga adicional, devem, ao contrário, aproveitar todas as oportunidades e produzir o que os consumidores desejam a partir de processos que permitam diferenciar seus produtos frente a outros artigos encontrados nos mercados.

É mister recordar que se trata de um documento recente (CEE, 2008) e que prevê quatro regimes de qualidade sob proteção, quais sejam: a) indicações geográficas; b) agricultura ecológica; c) especialidades geográficas garantidas; d) produtos procedentes das regiões ultraperiféri$\operatorname{cas}^{8}$ da UE. As indicações geográficas incluem as Denominações de Origem Protegidas (DOP) e as Indicações Geográficas Protegidas (IGP). A diferença entre ambas está no fato de que na DOP se exige que todas as fases de produção sejam realizadas numa zona delimitada e que as características do produto dependam exclusiva ou essencialmente de sua origem geográfica. Já no caso da IGP, ao menos uma das fases de produção deve realizar-se na própria região, sendo que o vínculo deve justificar-se a partir de uma qualidade específica, reputação ou outra característica relacionada com a zona geográfica em questão.

Através desses instrumentos buscam-se, simultaneamente, resguardar os produtores frente à concorrência deslea $1^{9}$ que acarretam os produtos de imitação comercializados com um mesmo nome e, por outra parte, assegurar aos consumidores a garantia de um produto elaborado mediante o cumprimento de normas estritas, cuja qualidade é assegurada por órgãos certificadores públicos ou privados.

DOP e IGP representam as figuras mais importantes no âmbito da UE, mas em setores como o vitivinícola há uma grande variedade de instrumentos de proteção, como é o caso dos vinhos de qualidade produzidos em regiões determinadas (VQPRD) e os vinhos de mesa com indicação geográfica, segundo define o Regramento 1493/99 (CE, 1999) 
e que estabelece, ademais, a organização comum do mercado vitivinícola e o conceito de VQPRD, com as seguintes categorias de vinhos de qualidade, produzidos em regiões determinadas: vinhos de licor; vinhos espumantes; vinhos brancos frisantes e, por fim, todos os demais vinhos.

No caso espanhol há que ressaltar que todas estas figuras europeias de proteção dos VQPRD têm sua correspondência nas figuras de proteção deste país, como são os vinhos de qualidade com indicação geográfica, com denominação de origem, com denominação de origem qualificada e os "vinhos de pago"10. Já no caso dos vinhos de mesa com indicação geográfica, sua transcrição no caso espanhol corresponde aos chamados "vinos de la tierra". É mister recordar que a Espanha ostenta uma forte tradição vinícola, bem como a maior superfície de vinhedos do planeta, possuindo atualmente 72 Denominações de Origem, 5 Denominações de Origem Qualificada, 4 Vinhos de Qualidade e 4 Vinhos de Pago, perfazendo um total de 85 indicações geográficas. Some-se a isso a existência de 141 produtos agroalimentares amparados por DOP e IGP, além de 16 DO ou IG das chamadas bebidas espirituosas ${ }^{11}$, segundo informações oficiais (MARM, 2010).

Ao longo do tempo, o que se constata é que as IGs foram estendidas a inúmeros setores e atividades, mas convém recordar, segundo alude Martín Cerdeño (2006:89), que até 1992 não se havia produzido o reconhecimento da UE para denominações de qualidade de outros produtos além do vinho. Tal ampliação demonstra o grau de importância que assumem tais figuras de proteção, bem como a necessidade de contar com um marco regulador onde caiba toda a diversidade que caracteriza o espaço europeu, em que pese o grande número indicações geográficas protegidas ${ }^{12}$.

Não obstante, há que recordar que logo abaixo das DOP e IGP estão os chamados lábeles regionales, como por exemplo os produtos Calidad diferenciada de Andalucía, Alimentos de Extremadura e um amplo leque de distinções que aludem à qualidade e singularidade de alimentos distribuídos por toda geografia espanhola.

Não resta dúvida acerca do papel transcendental que assumem as indicações geográficas e os produtos de qualidade diferenciada do ponto de vista do fomento ao dinamismo, à inovação e diversificação das áreas rurais. Mas também é certo que o panorama europeu, e sobretudo espanhol, é relativamente confuso, dado que nele se misturam le- 
gislações, propostas e figuras de proteção provenientes da União Europeia, do Estado espanhol e das 17 comunidades autônomas (Sainz, 2004:41).

O Regulamento (CE) 510/2006 (UE, 2006) relativo à proteção das IGs e DOs de produtos agroalimentares adverte sobre a necessidade de o consumidor dispor de informações claras e sucintas sobre a origem dos produtos. Não obstante, não há como negar os efeitos produzidos tanto pela proliferação de figuras de proteção, gerando confusão aos consumidores, quanto pela profusão de regimes de certificação de produtos.

Parece claro que a DO é uma condição necessária para acessar mercados cada vez mais exigentes, mas não é uma condição suficiente para atingir uma posição consolidada, sob o império da acirrada concorrência que acarreta a globalização dos mercados. Não obstante esses aspectos, parece lógico supor que as IGs esboçam uma dupla conexão entre, de um lado, o lugar geográfico e os processos de produção e, de outro, entre a qualidade do produto e o lugar onde o mesmo foi elaborado.

Reconhece-se que através das figuras de proteção não se quer apenas garantir a qualidade de um determinado produto, mas salvaguardar o entorno humano, físico, histórico e cultural que lhe deu origem. Nesse sentido, cabe advertir que:

Uma coisa é a valorização de um produto típico de forma isolada, outra coisa é reunir e tornar evidentes as conexões que possam existir entre distintos aspectos da realidade local: os produtos [...], os serviços [...], os conhecimentos técnicos disponíveis, o idioma. A projeção, em termos de identidade cultural, facilita a percepção do conjunto do sistema local, dando-lhe unidade e coerência. (Saraceno, 2007:185-186; tradução livre)

Essa perspectiva se apoia no entendimento de que a valorização dos produtos locais e o fortalecimento da identidade cultural de um território representam as duas faces de uma mesma moeda. Reativar esse tipo de produção e recuperar o patrimônio cultural têm sido apontados, no caso europeu, como responsáveis por gerar novas perspectivas a muitas zonas rurais deterioradas e escassamente integradas à sociedade mais ampla. Com isso, se passa a fomentar um turismo rural ba- 
seado no potencial de seu entorno natural e, sobretudo, cultural (Aguilar e Amaya, 2007:123).

Nesse sentido, a atuação dos Grupos de Ação Local criados na Espanha por força das sucessivas edições do Programa Leader converteu-se em um marco de referência para as políticas de desenvolvimento territorial em toda a Europa. Mas, se o balanço é francamente positivo sob a perspectiva dos logros alcançados, também é certo que o resgate de produtos com identidade cultural converteu-se na pedra angular de muitas destas exitosas experiências. A próxima seção analisa a questão da abordagem territorial de desenvolvimento e o tema das IGs no Brasil.

\section{ABORDAGEM TERRITORIAL DO DESENVOLVIMENTO E INDICAÇÕES GEOGRÁFICAS NO BRASIL}

Uma visão retrospectiva sobre a última década, com respeito à evolução das políticas de desenvolvimento rural nos países latinoamericanos, revela a incorporação, em maior ou menor medida, da abordagem territorial do desenvolvimento (Schejtman e Berdegué, 2003). Todavia, como alude Favareto (2007), nem sempre o resultado é satisfatório quando o exame é feito à luz da consistência dos instrumentos postos em funcionamento, cujas premissas foram anteriormente expostas. $\mathrm{O}$ caso brasileiro exemplifica essa assertiva.

A criação, em 2003, da Secretaria de Desenvolvimento Territorial (SDT) deve ser vista como representativa do empenho do governo federal no sentido de operar a transição da concepção setorial para a territorial em seus instrumentos de intervenção na realidade. Todavia, é mister recordar que se trata de uma secretaria criada para gerenciar os recursos de um outro programa (o Prona $\mathrm{f}^{13} \mathrm{em}$ sua vertente Infraestrutura), a qual se insere no corpo de um ministério (Desenvolvimento Agrário) cuja atuação é deveras limitada do ponto de vista da capacidade de concretar alianças com outras instâncias do governo federal, dos Estados e municípios.

Convergimos com Favareto (2007:14) quando este afirma que o grande desafio está justamente em superar um duplo viés que acomete a atuação do Estado brasileiro nesse âmbito, qual seja, o viés do combate à pobreza e o viés setorial que restringem as ações à esfera da agricultura. A criação dos "territórios da cidadania" espelha claramente os efeitos dessa tendência, cuja aparição responde aos anseios do Estado no 
sentido de conferir uma maior visibilidade para suas iniciativas no plano social. Consideramos válida a criação dos territórios no afã de conferir unidade e consistência à atuação estatal para além da escala do município, fomentando a formação de consórcios em regiões marcadas por graves problemas estruturais. Todavia, a ênfase na agricultura familiar como protagonista único e exclusivo do desenvolvimento e foco estrito no combate à pobreza impede a construção de alianças mais amplas com outras forças sociopolíticas e representam, na nossa acepção, uma grande contradição com os pressupostos da abordagem territorial.

Frente a este cenário é difícil imaginar que essa concepção possa ultrapassar a condição de simples inovação da retórica oficial. A leitura dos documentos referenciais da SDT para uma estratégia de desenvolvimento rural sustentável corrobora esse tipo de assertiva. Para os efeitos do presente artigo é importante observar que em nenhum momento é mencionada a questão das indicações geográficas no quadro dos instrumentos que sinalizam para o desenvolvimento dos territórios. Trata-se de uma discussão cujo teor escapa completamente ao escopo da atuação e objetivos da SDT cuja visão de desenvolvimento mostra-se demasiado restrita e totalmente incapaz de construir alianças mais amplas com outras instâncias governamentais requeridas para aumentar a densidade do tecido produtivo no contexto dos territórios. Feitas essas observações, cabe agora retomar o tema das indicações geográficas no Brasil e suas conexões com o argumento do presente artigo.

A legislação que dispõe sobre as IGs no Brasil segue as disposições que emanam dos acordos firmados pelos países integrantes do Mercado Comum do Cone Sul (Mercosul). O marco legislativo de proteção encontra-se no protocolo de harmonização de normas sobre propriedade intelectual em matéria de marcas, indicações de procedência e denominações de origem. Este documento (Lei no 912) foi aprovado na VIII Reunião do Conselho do Mercado Comum e Encontro Presidencial do Mercosul ocorrido em Assunção (Paraguai), entre 1 e 5 de agosto de 1995, o qual protege tanto as marcas de serviços quanto as marcas coletivas e de identificação (Mercosul, 1995).

Os países-membros criaram a "marca Mercosul", mas como reitera Benedetto (2007:152), falta muito para avançar nessa direção, se temos em mente que "ainda não existe um organismo coordenador da marca, 
que funcione como instância de identificação de produtos regionais com potencial exportador e que fomente e fiscalize a incorporação das normas internacionais de qualidade dos produtos" (tradução livre).

A bem da verdade, cabe frisar que desde 1995 negocia-se um acordo entre a União Europeia e os países do Mercosul sobre este tema. Mas é preciso ter em conta, como alude Niederle, que as tratativas nesse âmbito estão engessadas em virtude das assimetrias entre os blocos. Por outro lado,

De modo geral, os países do Mercosul evitam os termos sugeridos pela UE no que se refere ao tema das IGs. Mas existem posições contraditórias entre os países sulamericanos e, às vezes, dentro do mesmo país vide o caso do Brasil, único país representado por dois ministérios referentes à agricultura nas reuniões da OMC. Por um lado, estes países buscam desenvolver sistemas de indicações geográficas que reconhecem a importância deste mecanismo para o comércio internacional. Por outro, há quem trate a questão como uma espécie de "moeda de troca" na demanda para que a Europa remova barreiras de comércio e corte subsídios agrícolas, o que possibilitaria a países como Brasil e Argentina exercer suas vantagens comparativas no mercado internacional, notadamente no que tange ao setor do agronegócio. (Niederle, 2011:48; aspas no original)

Ou seja, o que aqui se quer evidenciar é que não obstante o interesse despertado pelas indicações geográficas por parte de diversos atores da esfera agroalimentar ou de outros setores econômicos (turismo, entretenimento, agentes culturais etc.), não cabe dúvida de que pouco se tem avançado nesta matéria nos países do Cone Sull ${ }^{14}$.

A experiência vivenciada no Vale dos Vinhedos, sobre a qual nos aprofundaremos mais adiante, corresponde a um dos casos de estudos por equipe liderada por Ranaboldo e Schejtman no âmbito latinoamericano, dentro do que tais autores denominam "produtos com identidade cultural". Uma das conclusões mais importantes a que chegam estes autores é no sentido de afirmar que, não obstante a enorme riqueza cultural desta parte do planeta, "são muito poucos os casos em que estas iniciativas conseguem articular-se dentro do território, diversificar-se e alcançar uma dinâmica e uma 'massa crítica' que lhes permitam incidir nos processos mais amplos de desenvolvimento numa escala territorial" (Ranaboldo, 2009:25; tradução livre; aspas no original). 
O marco legal das IGs no Brasil (Lei no 9.279 de 14/5/1996) é muito recente e contempla duas grandes figuras de proteção, quais sejam, as Indicações de Procedência (IP) e as Denominações de Origem (DO). A IP refere-se ao nome geográfico de um país, cidade, região ou localidade de um território e que se tornou conhecida como centro de obtenção, produção ou fabrico de um determinado produto ou de prestação de um serviço. Já a DO indica o nome geográfico do país, cidade, região ou localidade de seu território e que designa o produto ou serviço cujas qualidades ou características devam-se exclusiva ou essencialmente ao meio geográfico, incluindo fatores naturais e humanos.

A distinção entre tais figuras está no fato de que na IP o relevante é a notoriedade associada à qualidade que alcançou um determinado produto, ao passo que na $\mathrm{DO}$ a excelência deve estar obrigatoriamente associada aos aspectos físicos (solo, água, clima), humanos e culturais do meio onde ocorreu a obtenção ou produção.

Tanto a IP quanto a DO devem estar registradas no Instituto Nacional de Propriedade Industrial (INPI). Até 2010 havia apenas seis (6) indicações geográficas reconhecidas pelo INPI. Surgida em 2002, a IP dos vinhos finos e espumantes do Vale dos Vinhedos corresponde à primeira delas, seguida do café do Cerrado (2005), da carne bovina e derivados do Pampa Gaúcho da Campanha Meridional (2006), cachaça de Paraty (2007) e couro curtido do Vale dos Sinos (2009).

Não obstante, os dados do Gráfico 1 não deixam dúvidas acerca do vertiginoso incremento no número de IG brasileiras, o qual foi multiplicado 4,7 vezes no espaço de tempo correspondente aos últimos dois anos, e que, até o momento de elaboração deste artigo, compreendia 21 IPs e sete DOs (28 IGs no total).

É oportuno ressaltar que a legislação brasileira admite tramitar pedidos de registro de produtos nacionais e estrangeiros, havendo atualmente 26 solicitações que abarcam produtos alimentícios (vinhos, presuntos, água, queijo etc.), e inclusive não alimentícios (algodão, equipamentos eletrônicos, artefatos metálicos, couro etc.).

O Vale dos Vinhedos: A Valorização dos Vinhos e dos Encantos da Serra Gaúcha

O processo de colonização levado a cabo no Rio Grande do Sul durante a primeira e a segunda metade do século XIX exerceu enorme influên- 


\section{Gráfico 1}

Evolução das Indicações Geográficas

(Indicações de Procedência e Denominações de Origem) entre os anos 2002 e 2012

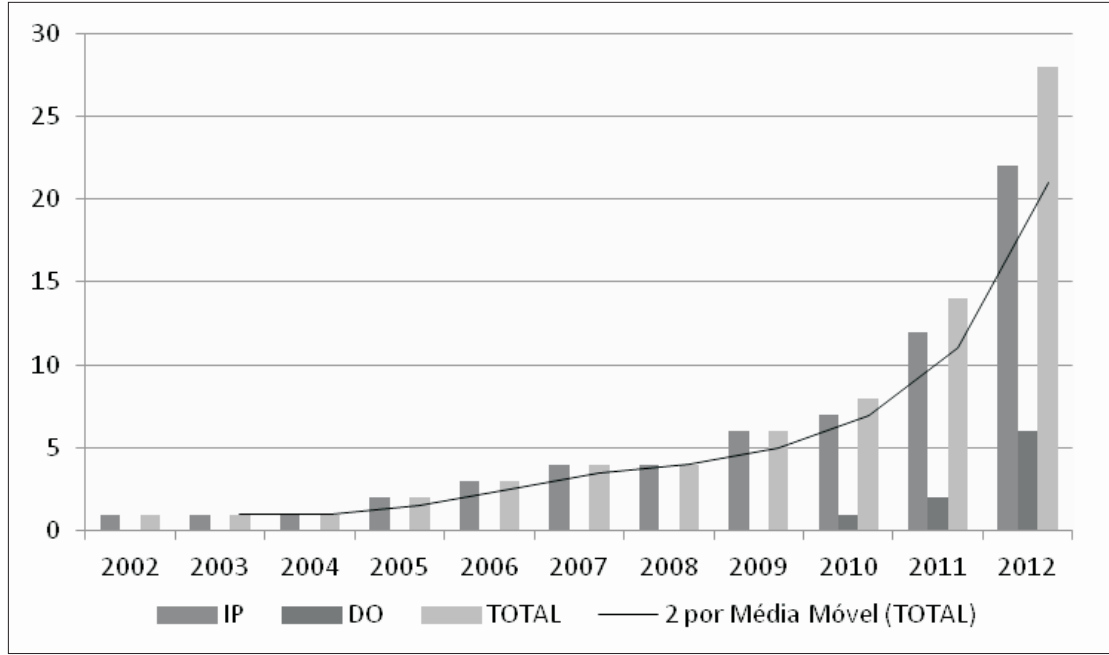

Fonte: Elaboração dos autores a partir dos dados do MDIC/INPI.

cia na conformação atual dessa unidade federativa. Nesse sentido, para o argumento central deste artigo importa destacar dois grandes efeitos desse processo, quais sejam, o de contribuir para a constituição de um dos mais importantes setores da agricultura familiar ${ }^{15}$ nacional e, por outra parte, de assentar as bases para consolidar a indústria regional.

Tais efeitos estiveram estreitamente ligados ao protagonismo exercido pelos colonos provenientes da Europa (alemães, poloneses e italianos), os quais incorporaram à sociedade gaúcha um ethos singular (Gaiger, 1994; Tedesco, 1999) que expressa os traços típicos do campesinato centro-europeu, principalmente seu dinamismo para a diversificação das atividades. Os analistas coincidem no entendimento de que as raízes da industrialização das zonas setentrionais desse Estado encontramse precisamente associadas ao florescimento desta "agricultura colonial" e ao processo de acumulação de riqueza daí resultante, um fenômeno para o qual foi muito importante o conhecimento técnico destes imigrantes.

Some-se a isso a intensa articulação que se foi desenvolvendo entre os interesses expansionistas de certos ramos de atividade fabril (metalúrgicas, têxteis, calçados, vinhos etc.) e as estratégias próprias das famíli- 
as rurais para garantir sua reprodução social, conferindo à dinâmica social e econômica destes territórios um traço diferencial frente a outras regiões do país e, inclusive, do próprio Rio Grande do Sul.

Para os objetivos do presente artigo importa destacar uma outra faceta deste cenário e que se associa à trajetória da imigração italiana numa região precisa deste Estado, qual seja, a chamada "Serra Gaúcha", conhecida como um importante destino turístico do Brasil meridional onde se produz atualmente $90 \%$ da produção nacional de vinhos (Gollo, 2006). Eé precisamente no interior dessa região que se encontra a primeira experiência de indicação de procedência do Brasil. A trajetória que acompanhou essa iniciativa não pode ser descrita sem aludir ao papel desempenhado pelos italianos que chegaram ao Estado em 1875.

Até o início do século XX o vinho era produzido com o objetivo de atender fundamentalmente o consumo próprio das famílias, utilizando-se variedades rústicas de uva. Mas a partir das décadas de 1970 e 1980 se ingressa em uma outra etapa da vitivinicultura com o aporte de capital internacional e a busca de aperfeiçoamento nos sistemas de produção, processo este impulsionado pela ampliação do mercado interno, cada vez mais aberto ao consumo de vinhos de melhor qualidade. Por essa época o Brasil adota uma política de incremento da qualidade centrada nos chamados "vinhos varietais". Todavia, como afirma Tonietto (2005:143), são vinhos cujo elemento de destaque não é a região produtora, mas a variedade da uva usada em sua elaboração.

O período subsequente coincide com uma série de mudanças entre as quais figura a criação do Mercosul e os efeitos que engendra sobre o setor vitivinícola nacional em face do ingresso dos vinhos procedentes do Uruguai e, particularmente, do Chile e Argentina em nosso país sob condições tarifárias que promovem uma feroz concorrência com o produto nacional. É justamente no rastro destas questões que se deve entender não somente a criação da Associação dos Produtores de Vinhos Finos do Vale dos Vinhedos (Aprovale), para defender os interesses dos produtores, mas sobretudo um conjunto de iniciativas centradas no objetivo de demonstrar o "efeito terroir" desta região sobre os vinhos elaborados ${ }^{16}$.

Desse modo o Brasil ingressa, como afirma Tonietto (2005:144), na produção dos vinhos de "quarta geração", que devem afirmar a identidade e qualidade do produto nacional, seja no plano do mercado interno 
que se enfrenta à aludida competência do artigo importado, seja no plano do leque de oportunidades que brindam os mercados internacionais.

A estratégia adotada culminou na aparição da indicação de procedência em 2002, através da qual são estabelecidos critérios de delimitação geográfica e criação de um Conselho Regulador. Esta IP abarca uma superfície de $81,23 \mathrm{~km} 2$ e se distribui por três municípios (Bento Gonçalves, Garibaldi e Monte Belo do Sul). Os produtos protegidos são os vinhos tintos, brancos e espumantes, havendo um conjunto de rigorosos procedimentos que devem ser cumpridos para que os mesmos levem a etiqueta "Vale dos Vinhedos". A A provale congrega atualmente 31 vinícolas, além de 28 associados que incluem hotéis, restaurantes, queijarias, pousadas e outras empresas.

A principal agência de pesquisa agrícola do Brasil (Embrapa) desempenhou um papel de destaque nesse processo, por meio do qual se buscava uma saída à crise produzida pelos vinhos estrangeiros. O principal agente articulador dessa iniciativa menciona ${ }^{17}$ este fator como decisivo para induzir ao processo que culminou na formação da Aprovale, num primeiro momento, e, num segundo momento, na criação da IP. Segundo suas próprias palavras:

o Vale dos Vinhedos é uma carta de apresentação, é um diferencial, contatar com o pessoal do Vale dos Vinhedos é um pessoal diferenciado... Isso aí ajuda a enfrentar esse mercado muito complicado, muito complicado. É um fator que tem ajudado, e essa é a ideia. Quando a gente começou a construir as indicações geográficas aqui no Brasil pra vinhos, se sabia que o mercado ia abrir porque tem gente muito boa nesse mundão afora, as regiões são cada vez melhores, investindo... Sem qualidade não se consegue nada.

Tal experiência gerou importantes efeitos, tanto interna quanto externamente à região. No primeiro caso há que mencionar os benefícios sobre os processos de produção vitivinícola, trazendo consigo a incorporação da rastreabilidade e os diversos mecanismos de controle da qualidade da uva e do vinho, mas também na perspectiva do fortalecimento de uma identidade regional calcada na alusão à história dos pioneiros e que se reflete no encanto de paisagens que incluem caminhos rurais, casarios de pedra e antigas cantinas, em meio a um cenário que em muito se assemelha ao distante Vêneto, à Lombardia ou ao Piemonte italiano. 
O êxito verificado na iniciativa do Vale dos Vinhedos induziu a que nessa região fossem criadas outras associações de produtores imbuídas do mesmo objetivo, qual seja, o da criação de uma IG, como é o caso da Aprobelo (Associação dos Vitivinicultores de Monte Belo do Sul), Afavin (Associação Farroupilhense de Vinicultores), Apromontes (Associação de Produtores dos Vinhos dos Altos Montes) e Asprovinho (Associação dos Produtores de Vinhos de Montanha). Tais associações encontram-se articuladas em torno de um ambicioso projeto nacional intitulado ${ }^{18}$ Wines of Brazil, cuja meta é dar a conhecer internacionalmente a qualidade e singularidade dos vinhos do país, no qual há um alto nível de protagonismo desta zona situada no interior da Serra Gaúcha ${ }^{19}$.

Se nos fixamos no âmbito externo, há que mencionar que esta experiência contribuiu para impulsionar o florescimento de outras experiências de IG no Rio Grande do Sul (Carne do Pampa Meridional Gaúcho e Couros do Vale dos Sinos) e em outras regiões do país como é o caso da Cachaça do Brasil e do Café do Cerrado.

Entretanto, o Vale dos Vinhedos enfrenta algumas dificuldades relacionadas com o esforço de conciliar os distintos interesses implicados (públicos e privados) e sedimentar as bases para uma estratégia territorial de longo prazo. Um dos grandes problemas resulta do protagonismo excessivo das grandes vinícolas em virtude do considerável peso econômico e político que lhes correspondem no plano local e regional. O contato com os atores que interagem nesse cenário detectou alguns discursos que se chocam frontalmente com as virtuosidades do "Vale dos Vinhedos".

Referimo-nos, especialmente, às organizações não governamentais ligadas à produção ecológica que consideram que esta iniciativa reproduz os mesmos mecanismos de extração do sobretrabalho dos produtores familiares. Além disso, argumentam que há um claro desprestígio com relação à produção vitivinícola gerada através de variedades rústicas como no caso da cultivar Isabel, que, apesar de produzir um vinho considerado inferior, demanda uma carga bem menor de agrotóxicos em seu sistema de produção se comparada ao das uvas finas ${ }^{20}$.

Ainda assim, o balanço ${ }^{21}$ da iniciativa é muito positivo, particularmente por favorecer a emergência de uma série de empreendimentos cujo atrativo essencial reside no chamado "enoturismo". Nesse mesmo espaço (Serra Gaúcha) e sob o mesmo tipo de apelo - a cultura italiana e 
os encantos do seu entorno natural e paisagístico - levaram-se a cabo outros processos de valorização da identidade regional, como é o caso dos "Caminhos de Pedra". A identidade étnica ítalo-brasileira, forjada na saga dos imigrantes, ergue-se a partir da exaltação de certos traços (religiosidade, campesinidade, gastronomia ou a ética do trabalho) que, conjuntamente, são decisivos na ativação de um imaginário social claramente identificável.

A arquitetura típica dos casarões de pedra e a beleza dos caminhos rurais se conectam de forma harmônica com a atmosfera mágica do mundo do vinho. É um processo recente que exigiu uma série de medidas, não somente orientadas a recuperar e preservar o patrimônio material na montagem de rotas turísticas, mas especialmente em prol do resgate de certos bens imateriais (idioma, folclore, arte e habilidades manuais etc.) e profissionalização dos atores locais (Cerdan et alii, 2009:307).

Mas não restam dúvidas de que existem importantes diferenças entre a iniciativa Vale dos Vinhedos e a dos Caminhos de Pedra. Assim, enquanto a primeira revela uma estratégia típica de agregação de valor a uma cadeia de produto (vinhos e espumantes), a segunda representa uma estratégia típica de "cesta de bens", muito mais vinculada ao desenvolvimento integral do território.

Acampora e Fonte (2007:194) destacam que a estratégia de cadeia está centrada na valorização de um produto específico, portador de uma identidade cultural que lhe permite viajar a mercados distantes sem romper os vínculos com suas origens. Já no caso da estratégia "cesta de bens", trata-se de valorizar a identidade territorial, não por meio de um único produto, senão através de uma cesta de bens dentro da qual um dos "marcadores de identidade" pode ser o grande protagonista, a exemplo do vinho.

Assim, enquanto no caso da primeira via se privilegia, claramente, os vínculos verticais, na segunda a primazia recai sobre os vínculos horizontais entre os atores envolvidos. Mas é importante destacar que as duas estratégias podem conviver, sendo perfeitamente compatíveis, convergentes e/ou complementares, se temos em mente que o vinho representa não somente a ideia de um artigo tradicional, com toda carga de subjetividade, mas sobretudo por cristalizar as características singulares do território e a herança cultural desta peculiar região do país. 
Encontramo-nos diante de duas experiências que surgiram muito mais como resultado da iniciativa dos próprios sujeitos envolvidos nesses processos do que propriamente por força da existência da atuação do poder público. O conhecido empreendedorismo dos descendentes de italianos, a que anteriormente nos referimos, ergue-se como a força essencial que impulsionou tais iniciativas. Esse tipo de atributo também está presente no caso europeu, mas não se pode desconsiderar a existência de um ambiente institucional (Abramovay, 2005) que conspirou fortemente em seu favor, especialmente a partir do advento das iniciativas Leader e Proder em suas sucessivas edições.

Há diversas lições que pudemos extrair a partir da imersão que vimos desenvolvendo na região em tela a partir das entrevistas realizadas com os diversos atores sociais. A primeira delas é que a IPVV não pode ser vista simplesmente como uma mera ferramenta mercadológica de promoção de um produto de qualidade diferenciada, mas sim como um instrumento de desenvolvimento ancorado num território específico e que se nutre de uma herança cultural e histórica extremamente potente, em torno do qual outras iniciativas possam aflorar (o turismo, a gastronomia, a prestação de serviços etc.).

Mas será que os resultados dessa construção capitaneada pela indicação geográfica fortalecem, efetivamente, a plenitude dos setores constituintes do tecido social e produtivo de um dado território? Esta questão remete o leitor para uma discussão que extrapola os limites deste estudo. Consideramos, deste modo, que é necessário um acúmulo de experiências que nos permitam afiançar a veracidade desta hipótese.

Outrossim, o que está claro é que a evolução do mondovino e a necessidade de adaptação a um cenário cada vez mais competitivo e desafiador fizeram emergir uma experiência que se baseia fundamentalmente na confiança, na cooperação e na capacidade de inovação de diversos atores. Tal ambiente fez surgir estruturas de governança (Conselho Regulador) que atualmente exercem suas funções para além do universo da vitivinicultura, como no caso de influir na discussão sobre o plano diretor dos municípios que conformam a indicação geográfica com a finalidade de frear a especulação imobiliária ${ }^{22}$, notadamente a criação de condomínios de luxo na área delimitada.

A construção das antigas capelas e centros comunitários, a criação de associações locais para gerir a distribuição de água, o financiamento assumido de forma compartilhada pelas famílias para construção e ex- 
tensão de redes de eletrificação e de telefonia podem ser vistos como manifestação do capital social de uma região que, obviamente, extrapola a área delimitada pela IPVV. Todavia, também é certo dizer que a estes aspectos somam-se outras questões igualmente importantes, como é a preocupação em preservar a beleza cênica de paisagens desenhadas pela mão do homem, como é o caso dos parreirais, dos caminhos rurais e dos velhos casarões de pedra.

Coincidimos com Ortega e Jeziorny (2011:117) quando estes concluem: "Portanto, é cabível de se entender que, no Vale dos Vinhedos, há reciprocidade, cooperação, número de jogadores e informações a respeito da reputação de cada indivíduo. É justamente a existência de todas essas condições que, segundo Putnam $(2000)^{23}$, facilita o surgimento de um bom estoque de capital social".

O caso da IPVV, que hoje conquistou a condição de "Denominação de Origem" para seus vinhos e espumantes, demonstra, de forma cabal, que a competição e a cooperação não podem ser vistas como vetores que se opõem ou se excluem mutuamente. As empresas que se organizam em torno de um projeto dessa natureza, que inclui uma plêiade de iniciativas (sobretudo as ligadas ao enoturismo), buscam, de forma coordenada e articulada, veicular uma imagem do próprio território e uma narrativa centrada na própria identidade. E, se essa construção exprime com bastante clareza o que vimos aqui comentando, parece igualmente interessante reproduzir a pergunta feita por Durston (1998) na epígrafe de seu trabalho: "como criar capital social onde ele não existe?". A resposta a esta questão tem a ver com a tentativa de explicação para o fato de que outras iniciativas do gênero não avançaram no Rio Grande do Sul e no Brasil, mesmo após a criação de dispositivos dessa ordem, como é o caso da Indicação de Procedência da Carne e Derivados do Pampa Gaúcho da Campanha Meridional ou mesmo da primeira Denominação de Origem brasileira (Arroz do Litoral Norte), que literalmente, não avançaram em seus propósitos.

\section{CONSIDERAÇÕES FINAIS}

Não resta dúvida de que os cenários europeu e brasileiro são muito distintos do ponto de vista dos resultados e das circunstâncias que obram em favor da emergência destas novas dinâmicas de desenvolvimento e inovação centradas nos produtos com identidade cultural. Por outro lado, crescem os desafios que se devem enfrentar, no caso europeu, di- 
ante dos problemas trazidos pela recente proliferação de marcas e figuras de proteção, muitas das quais surgidas ao sabor das políticas de desenvolvimento territorial.

Decididamente o coração de uma indicação geográfica reside em seu conselho regulador, cujas atribuições extrapolam o mero estabelecimento de um pliego de condiciones para a produção de um determinado artigo, especialmente em face do papel transcendental que adquire na conciliação de interesses, na administração de conflitos e na busca de soluções para problemas que afetam ao conjunto dos atores sociais. Todavia, não coincidimos com certas análises que colocam demasiado otimismo no potencial das IGs como instrumento capaz de impulsionar, por si só, o desenvolvimento equilibrado dos territórios.

Os estados meridionais do Brasil contam com algumas infraestruturas produtivas mais eficientes em relação ao resto do país e lograram alcançar alguns êxitos na valorização de produtos regionais. Mas a realidade mostra que muitas dessas iniciativas se aferram a uma visão estritamente setorial e agrarista que dificulta, sobremaneira, o estabelecimento de vínculos horizontais para além da cadeia de um determinado produto e do âmbito local.

O balanço sobre os êxitos alcançados pelas políticas de desenvolvimento na UE é francamente positivo, mas não se pode desconsiderar o papel desempenhado pelos atores sociais e o caráter inovador da metodologia Leader. No Brasil as iniciativas de desenvolvimento rural são invariavelmente executadas pelo serviço de extensão agrária ou por organizações não governamentais que, via de regra, não se mostram identificados com as premissas da abordagem territorial. A ênfase segue sendo o apoio a cadeias agroalimentares e na verticalização dos processos produtivos.

Por outro lado, admite-se que é insuficiente o marco jurídico e normativo brasileiro no que toca à proteção dos produtos típicos e isso se deve, em parte, ao reduzido número de indicações geográficas existentes nesse país, se comparado com o caso da Espanha e da UE.

A experiência do Vale dos Vinhedos cobra importância por duas grandes razões. Em primeiro lugar, porque se trata da primeira indicação geográfica do Brasil, convertida agora denominação de origem, cuja influência foi decisiva para animar o surgimento de outras iniciativas do gênero no país. Em segundo lugar, porque representa um exemplo 
gráfico do que se pode avançar em matéria de desenvolvimento. Nessa região coabitam duas estratégias distintas, mas não excludentes, de fortalecimento de uma identidade cultural comum que se busca projetar para o mundo exterior.

Nesse sentido, se o Vale dos Vinhedos é uma estratégia típica de agregação de valor a um produto rural, os Caminhos de Pedra configuram uma estratégia típica de "cesta de bens", mais vinculada ao desenvolvimento integral do território. Mas em ambos os casos se evoca uma mesma matriz cultural que descansa sobre o imaginário social construído em torno à trajetória da colonização italiana no Sul do Brasil - a Serra Gaúcha - cujos traços socioculturais são indiscutivelmente marcantes.

A cultura material (casas de pedra, caminhos rurais, antigas cantinas etc.) conecta-se de forma indissolúvel com a cultura imaterial resgatada pelos atores sociais do território que evocam valores como a campesinidade, a ética do trabalho, a religiosidade e toda a tradição herdada dos antepassados procedentes, especialmente, das zonas setentrionais de velha Itália.

E é por esse motivo que se quer aqui sublinhar a necessidade de estabelecer uma base conceitual mais ampla que contemple os aspectos relativos à identidade cultural dos territórios no centro dos mecanismos de intervenção estatal. Mas para isso torna-se imperativo contar com instrumentos políticos mais integrados, assim como romper com a visão setorial que associa os espaços rurais ao cumprimento de funções estritamente produtivas. As indicações geográficas podem converter-se em instrumento para o desenvolvimento territorial, sempre e quando outras condições e circunstâncias estejam presentes, sobretudo quando se pensa na necessidade de constituir um sujeito coletivo em torno de uma ideia guia que expresse a capacidade de articulação dos vetores dinâmicos do território.

(Recebido para publicação em abril de 2010)

(Reapresentado em novembro de 2012)

(Aprovado em fevereiro de 2013) 


\section{NOTAS}

1. Esse é o caso da FAO e IICA. Ver a propósito Riveros et alii (2008).

2. O projeto CAPES-COFECUB “Pluralité des signes de qualité et ajustements institutionels em France et au Brésil. Contributions pour la production de politiques de dévelopment rural durable", coordenado por John Wilkinson e Claire Delfosse, representa outra iniciativa de pesquisa dirigida a explorar a questão das IGs no contexto do desenvolvimento territorial. Ver a propósito Wilkinson (2008).

3. LEADER é o nome com que se identifica as sucessivas iniciativas (LEADER I, LEADER II, LEADER PLUS) comunitárias de Desenvolvimento Rural da UE. Corresponde à sigla, em francês “Liaisons entre activités de Developement de L'Economie Rural" (Relações entre Atividades de Desenvolvimento da Economia Rural). PRODER é o nome do "Programa Operativo de Desenvolvimento e Diversificação Econômica de zonas Rurais", destinado a impulsionar o desenvolvimento de zonas rurais desfavorecidas e a busca de alternativas econômicas viáveis no meio rural.

4. Ver a propósito Velasco et alii (2008).

5. A expressão em epígrafe deriva do inglês partner (parceiro) e faz parte do glossário das políticas de desenvolvimento rural da UE. Sinteticamente pode ser definido como uma aliança entre organizações de caráter público e privado, ideologicamente afinadas com uma visão de desenvolvimento, tendo em vista a planificação do processo de intervenção no território.

6. Some-se a isso os efeitos da recente crise econômica que confere sombras e incertezas aos países da UE, sobretudo àqueles que integram atualmente a chamada zona Euro.

7. Ver também Gómez (2004).

8. Corresponde aos departamentos franceses de ultramar (Guiana, Martinica, Guadalupe e La Reunión), Ilhas Canárias (Espanha), Açores e Madeira (Portugal).

9. O marco fundamental destes dispositivos de diferenciação é o chamado "Acordo sobre aspectos dos direitos de propriedade intelectual relacionados com o comércio" (ADPIC), estabelecido em 1994, cuja supervisão ocorre no âmbito da Organização Mundial do Comércio. O Acordo ADPIC não determina a legislação nacional, mas em observância aos termos deste acordo, os Estados signatários devem estabelecer um mínimo de proteção aos direitos de propriedade individual previstos no mesmo.

10. Essa classe de VQPRD corresponde à mais pura expressão do efeito terroir de um vinho. Entende-se que são originários de um pago, entendido como um local com características edafo-climatológicas que o diferenciam de outros vinhos de seu entorno, o qual é conhecido por um nome tradicional, cuja área máxima deve ser limitada pela administração competente. A produção de uva, elaboração do vinho e engarrafamento devem ocorrer dentro "do pago".

11. Trata-se de bebida que contém conteúdo alcoólico procedente da destilação de matérias primas agrícolas (uva, cereais, frutos secos, beterraba, cana de açúcar, frutas etc.), a exemplo do Brandy, Rum, Genebra, Vodka, licores, entre outros.

12. Um queijo de ovelha tradicional da Sicília converteu-se, em fevereiro de 2011, na denominação de qualidade número 1000 registrada no sistema da comissão de etiquetado de qualidade de produtos agrícolas e alimentares dos países integrantes da UE. 
Se a esses dados agregarmos as 1.334 DOP e 587 IGP de vinhos, chegaremos a um universo de 2.921 produtos registrados na UE.

13. Programa Nacional de Fortalecimento da Agricultura Familiar.

14. Como bem definiu Ortiz (2004), o Mercosul segue sendo uma estratégia de segundo piso. Ou seja, primeiramente os países definem suas estratégias, sendo que o Mercosul deve ser funcional a elas e não o contrário, como deveria ser.

15. Tal importância reside não exatamente no número de produtores identificados com estas características e que somam 400 mil estabelecimentos rurais nesta unidade federativa brasileira, mas sobretudo pelo conhecido dinamismo e presença nos mercados nacionais e estrangeiros, a exemplo das grandes cadeias de produtos de exportação (tabaco, soja, carnes e derivados, hortifrutícolas etc.).

16. O interessante estudo de Barco et alii (2007) descreve a convivência de dois modelos de produção e de duas estratégias comerciais personificadas em dois grandes grupos que atuam no setor vitivinícola no plano mundial. O primeiro deles é representado pelos países produtores tradicionais (PPT), localizados na Europa; o outro corresponde ao dos novos países produtores (NPP), situados na América do Norte, África e Oceania. Mas, se a base do modelo NPP apoia-se na atuação de grandes empresas e forte protagonismo dos vinhos varietais, no caso dos PPT a estratégia dominante recai na identificação dos vinhos com os territórios e nos mecanismos de proteção e garantia da qualidade. O exemplo do Vale dos Vinhedos, como se quer aqui demonstrar, serve para reafirmar a tese da inexistência de modelos únicos, assim como do suposto êxito de um ou outro grupo.

17. Entrevista concedida no dia 28 de abril de 2008 no município de Bento Gonçalves, RS.

18. Ver a propósito: http://www.winesofbrasil.com/Defaultãpt.aspx

19. Entre as conquistas da Aprovale deve-se mencionar o reconhecimento do Vale dos Vinhedos, em 2007, pela União Europeia, o que permitiu a exportação, nesse mesmo ano, de 435 mil litros de vinho, uma modesta quantidade que corresponde a $35 \%$ da produção certificada (Niederle, 2009:12) mas interessante para acalentar o sonho de abertura de novos mercados.

20. Guardadas as devidas proporções, trata-se de um enfrentamento similar ao verificado no caso espanhol no caso do azeite de oliva e que coloca, em trincheiras opostas, dois grandes grupos. De um lado, os produtores ligados às denominações de origem e, de outro, os que se identificam como produtores do azeite ecológico. Por mais segmentado que seja o mercado de azeites de qualidade, não resta dúvida de que existe uma acirrada disputa entre duas concepções que defendem a qualidade do seu produto.

21. Um dos grandes logros associados à iniciativa "Vale dos Vinhedos" está no sentido de conter o avanço do processo de urbanização sobre as áreas rurais, particularmente no município de Bento Gonçalves.

22. Curiosamente é esse um dos grandes desafios enfrentados pelos produtores de uva e vinho da região italiana de Chianti. Ver a propósito o estudo de Brunori e Rossi (2007).

23. Os autores se referem ao trabalho já citado, por nós, anteriormente. 


\section{REFERÊNCIAS BIBLIOGRÁFICAS}

ABRAMOVAY, Ricardo. (2005), “Um Novo Contrato para a Política de Assentamentos”, in P. M. Oliva (org.), Economia Brasileira-Perspectivas do Desenvolvimento. São Paulo, Ed. CAVC, pp. 355-375.

ACAMPORA, Teresa e FONTE, Maria. (2007), “Productos Típicos, Estrategias de Desarrollo Rural y Conocimiento Local”. Opera, no 7, pp. 191-212.

AGUILAR CRIADO, Encarnación e AMAYA CORCHUELO, Santiago. (2007), “El Patrimonio Cultural como Activo del Desarrollo Cultural”, in J. Sanz Cañada (ed.), El Futuro del Mundo Rural: Sostenibilidad, Innovación y Puesta en Valor de los Recursos Locales. Madrid, Editorial Síntesis, pp.104-124.

AGUILAR CRIADO, Encarnación; MERINO BAENA, Dolores e MIGENS FERNÁNDEZ, Mercedez. (2003), “Cultura, Políticas de Desarrollo y Turismo Rural en el Ámbito de la Globalización”. Horizontes Antropológicos, ano 9, no 20, pp.161-183.

BARCO, Emilio; CRUZ NAVARRO, Maria e PINILLOS, Mariola. (2007), “Estrategias de Diferenciación versus Estrategias de Tamaño. El Caso de la DOCa Rioja". Revista Española de Estudios Agrosociales y Pesqueros, no 215-216, pp. 13-45.

BENEDETTO, Andrea. (2007), “Valorización de la Identidad Territorial, Políticas Públicas y Estrategias de Desarrollo Territorial en los Países del Mercosur". Opera, no 7, pp. 139-165.

BRASIL, Presidência da República. (1996), Lei no9.279 de 14 de maio de 1996. Disponível em: http://www.planalto.gov.br/CCIVIL/Leis/L9279.htm. Acessado em $15 / 8 / 2008$.

BRUNORI, Gianluca e ROSSI, Adanela. (2007), “Differentiating Countryside: Social Representations and Governance Patterns in Rural Areas with Social Density: The Case of Chianti, Italy". Journal of Rural Studies, vol. 23, pp.183-205.

CE. (1999), Reglamento № 1493/99 del Consejo por el que se establece la organización común del mercado vitivinícola, Diario Oficial de la Unión Europea, de 14 de julho.

CEE (Comisión de las Comunidades Europeas). (2008), Libro Verde sobre la Calidad de los Productos Agrícolas, Normas de Comercialización, Requisitos de Producción y Regímenes de Calidad. Disponível em: http:/ / eur-lex.europa.eu/LexUriServ/LexUriServ. do? uri=COM:2008:0641:FIN:ES:PDF. Acessado em 7/10/2009.

CERDAN, Claire; SOUZA, Maria Célia Martins e FLORES, Murilo. (2009), “El Patrimonio Cultural como un Elemento Estratégico para el Desarrollo Territorial: Dos Casos de la Inmigración Italiana en Brasil", in C. Ranaboldo e A. Schejtman (eds.), El Valor del Patrimonio Cultural, Territorios Rurales, Experiencias y Proyecciones Latinoamericanas. Lima, IEP/Rimisp, pp. 303-319.

DE LOS RÍOS-CARMENADO, Ignacio; DÍAZ-PUENTE, José Maria e CADENAIÑIGUEZ, Jorge. (2011), “La Iniciativa Leader como Modelo de Desarrollo Rural: Aplicación a algunos Territorios de México". Agrociencia, vol. 45, no 5, pp. 609-624.

DURSTON, John. (1998), “Building Social Capital in Rural Communities (where it doesn't exist). Theoretical and Policy Implications of Peasant Empowerment". Traba- 
lho apresentado na reunião annual da Latin American Studies Association (LASA), The Palmer House Hilton, Chicago, Il, 24-26 de setembro.

FAVARETO, Arilson. (2007), Paradigmas do Desenvolvimento Rural em Questão. São Paulo, Fapesp/Ed. Iglu.

FLIGSTEIN, Neil. (2001), "Social Skill and the Theory of Fields". Sociological Theory, vol. 19 , no 2, pp. 105-125.

GAIGER, Luiz Inácio. (1994), "A Práxis Coletiva dos Sem-Terra Rumo à Unidade ou à Heterogeneidade Cultural?". Cadernos de Sociologia, no 6, pp. 177-203.

GOLLO, Silvana Sainara. (2006), “Delineamento e Aplicação de Framework para Análise das Inovações numa Perspectiva de Processo Interativo: Estudo de Caso da Indicação de Procedência Vale dos Vinhedos - Serra Gaúcha/RS". Teoria e Evidência Econômica, vol. 14, pp. 247-277.

GÓMEZ, Natalia. (2004), Construcción de un Proyecto de Territorio fundado en su Capital Territorial. Aplicando los principios del enfoque territorial del Programa Europeo LEADER en el Municipio de Gachancipá, Cundinamarca. Tese de doutorado sobre Desenvolvimento Rural, Pontifícia Universidad Javeriana, Bogotá.

GONZÁLEZ VARAS, Ignacio. (2006), Conservación de Bienes Culturales. Teoría, Historia, Principios y Normas. Madrid, Ediciones Cátedra.

HERVIEU, Bertrand. (1996), Los Campos del Futuro. Madrid, Ed. MAPA.

LETABLIER, Marie Thérèse e DELFOSSE, Claire. (1995), “Genése d'une Convention de Qualité", in G. Allaire e R. Boyer (eds), La Grande Transformation de l'Agricultura. Paris, INRA/Económica.

LOZANO CABEDO, Carmen Maria. (2009), Agricultura Ecológica y "Segura”. Multifuncionalidad, Calidad y Territorio en el Contexto de la Globalización. Sevilla, Universidad de Sevilla.

MARM (Ministerio de Medio Ambiente y Medio Rural y Marino). (2010), Disponível em: http:/ / www.mapa.es/alimentacion/pags/denominacion/documentos/vinos07_ 08.pdf. Acessado em 26/2/2010.

MARTÍN CERDEÑO, Víctor. (2006), “Denominaciones de Origen: Una Revisión en el Mercado Alimentario Español”. Distribución y Consumo, no 90, pp. 87-113.

MERCOSUR. (1995), Ley no 912. Protocolo de Armonizacion de Normas sobre Propiedad Intelectual en el Mercosur, en Materia de Marcas, Indicaciones de Procedencia y Denominaciones de Origen. Disponível em: http://www.cej.org.py/games/Leyes_por_Materia_ juridica/MERCOSUR/LEY\%20N\%C2\%BA\%20912.pdf. Acessado em 15/8/2008.

MOYANO ESTRADA, Eduardo. (2005), “Nuevas Orientaciones de la Política Europea de Desarrollo Rural. A propósito del nuevo reglamento de desarrollo rural". IESA-CSIC Working Paper Series, Documento de Trabajo no 514.

NIEDERLE, Paulo André. (2011), Compromissos para a Qualidade: Projetos de Indicação Geográfica para Vinhos no Brasil e na França. Tese de doutorado em Ciências Sociais, Programa de Pós-Graduação em Ciências Sociais em Desenvolvimento, Agricultura e Sociedade, Universidade Federal Rural do Rio de Janeiro, Rio de Janeiro. 
. (2009), “Controvérsias sobre a Noção de Indicações Geográficas enquanto Instrumento de Desenvolvimento Territorial: A Experiência do Vale dos Vinhedos em Questão". Anais do 47ํㅡㅁ Congresso da Sociedade Brasileira de Economia, Administração e Sociologia Rural. Porto Alegre.

ORTEGA, Antonio César e JEZIORNY, Daniel Lemos. (2011), Vinho e Território. A Experiência do Vale dos Vinhedos. Campinas, Alínea.

ORTIZ, Ricardo. (2004), “El Mercosur y la Argentina. Reflexiones críticas”. Tesis, Universidad Nacional de Cuyo, Mendoza, Argentina.

RANABOLDO, Claudia. (2009), "Recorridos de una Mirada Latinoamericana”, in C. Ranaboldo e A. Schejtman (Eds.), El Valor del Patrimonio Cultural: Territorios Rurales, Experiencias y Proyecciones Latinoamericanas. IEP/Rimisp, pp. 13-38.

RIVEROS, Hernando et alii. (2008), Calidad de los Alimentos Vinculada al Origen y las Tradiciones en América Latina: Estudios de Casos. Lima, FAO-IICA.

SAINZ, Hector. (2004), "Panorama de las Denominaciones de Origen y de Calidad Diferenciada en España". Cuadernos de la Tierra, no 3, pp. 41-46.

SANZ CAÑADA, Javier. (2007), “Calidad y Signos Distintivos. Las Denominaciones de Origen de Aceite de Oliva en España", in J. Sanz Cañada (ed.), El Futuro del Mundo Rural: Sostenibilidad, Innovación y Puesta en Valor de los Recursos Locales, Madrid, Editorial Sínteses, pp.175-198.

SARACENO, Elena. (2007), "Políticas Rurales de la Unión Europea y Proyectos Territoriales de Identidad Cultural". Opera, no 7, pp.167-189.

SCHEJTMAN, Alexander e BERDEGUÉ, Julio. (2003), “Desarrollo Territorial Rural”, in R. Echeveria (ed.), Desarrollo Territorial Rural en América Latina y el Caribe: Manejo Sostenible de Recursos Naturales, Acceso a Tierras y Finanzas Rurales. Washington, D.C., BID.

TEDESCO, João Carlos. (1999), “Contratualização e Racionalidade Familiar”, in J. C. Tedesco (org.), Agricultura Familiar: Realidades e Perspectivas. Passo Fundo, Ed. UPF.

TONIETTO, Jorge. (2005), “Experiências de Desenvolvimento de Indicações Geográficas: Vinhos da Indicação de Procedência Vale dos Vinhedos", in V. Lages; L. Lagares e C. L. Braga (orgs.), Valorização de Produtos com Diferencial de Qualidade e Identidade: Indicações Geográficas e Certificações para Competitividade nos Negócios. Brasília, Sebrae.

UE/MEMO 03/160, 2012 http://europa.eu/rapid/press-release_MEMO-03-160_es. htm?locale=en\#PR_metaPressRelease_bottom

UNIÃO EUROPEIA. (2012), Documento sobre Indicações Geográficas e Programa Leader.

UNIÓN EUROPEA. (2006), Reglamento (CE) no 510/2006 del Consejo, de 20 de março, Diario Oficial de la Unión Europea, 31 marzo (en línea). Disponível em: http:/ / eur-lex.europa.eu/LexUriServ/LexUriServ.do?uri= OJ:L:2006:093:0012: 0025:ES:PDF, Acessado em 15/9/2008.

VELASCO ARRANZ, Ana; MOYANO ESTRADA, Eduardo e SACCO DOS ANJOS, Flávio. (2008), "Contratos Territoriais de Estabelecimento na França: Rumo a um Novo Pacto Social na Agricultura?" Ambiente E Sociedade, vol. XI, no 2, pp. 219-235.

WILKINSON, John. (2008), Indicações Geográficas no Brasil: Situação Atual e Perspectivas. Trabalho apresentado no Seminário Internacional Indicações Geográficas no Brasil, 6 e 7 de novembro, Florianópolis, UFSC. 


\begin{abstract}
Geographical Indications, Identity and Development: A Dialogue between the European and Brazilian Reality

The article discusses the topic of the Geographical Indications in Europe and Brazil from the point of view of the territorial development. In case of Brazil the authors puts on special accent in the experience of the Valley of the Vineyards to which considers like representative of processes of innovation in the rural area. But the authors underline the need to establish a conceptual base more wide that contemplates the aspects relative to the cultural identity of the territories, in the center of the strategies of intervention, and not only from the optics of the dynamics of a chain of value of a certain product, process or service. But for so much it is necessary to rely on a few more integrated political instruments, as well as to break with the sectorial vision that associates the rural spaces with the strict fulfillment of productive functions.
\end{abstract}

Keywords: territorial development; territory; geographical indications; denominations of origin; Valley of the Vineyards

\title{
RÉSUMÉ
}

Des Indications Géographiques, Identité et Développement: Un Dialogue entre la Réalité Européenne et Brésilienne

L'article discute le sujet des indications géographiques en Europe et au Brésil du point de vue du développement territorial. Dans le cas du Brésil un accent spécial devient dans l'expérience de la Vallée des Vignobles à laquelle il considère comme représentative des processus d'innovation dans le domaine rural. Mais les auteurs soulignent la nécessité d'établir une base conceptuelle plus ample qui contemple les aspects relatifs à l'identité culturelle des territoires, au centre des stratégies d'intervention, et non seulement depuis l'optique des externalidades d'une chaîne de valeur d'un produit déterminé, de processus ou de service. Mais pour tant il est nécessaire de disposer de quelques instruments politiques plus intégrés, ainsi que casser avec la vision sectorielle qui associe les espaces ruraux à l'accomplissement strict de fonctions productives.

Mots-clés: développement territorial; territoire; indications géographiques; appellations d'origine; une Vallée des Vignobles 